\title{
Chlamydial infection of the cervix in contacts of men with nongonococcal urethritis
}

\author{
I ANNE TAIT,* ELISABETH REES, ${ }^{*}$ D HOBSON, $†$ RUTH E BYNG, $†$ \\ AND M C K TWEEDIE \\ From the Departments of *Venereology, + Medical Microbiology, and $\ddagger$ Biostatistics, University of \\ Liverpool, Royal Liverpool Hospital, Liverpool
}

SUMMARY An investigation of chlamydial infection in sexual contacts of patients with nongonococcal urethritis (NGU) was carried out to determine the clinical signs of infection in the cervix, and their response to chemotherapy, and the incidence of cervical infection in the presence of ectopy and oral contraception.

In 202 consecutive female contacts of NGU the isolation rate of Chlamydia trachomatis was $35 \%$. Hypertrophic ectopy and endocervical mucopus were present in $19 \%$ and $37 \%$ of chlamydia-positive patients respectively and, in all but one, resolved after treatment. Only 14\% of those followed up after treatment developed yeast infections. The chlamydial isolation rate was significantly higher in patients with hypertrophic ectopy and endocervical mucopus. Cervical ectopy and oral contraceptives acted additively, each producing a significant effect on the chlamydial isolation rate in the presence of the other but not when present alone.

\section{Introduction}

The clinical diagnosis of nongonococcal urethritis (NGU) in men is often arbitrary and commonly based solely on the finding of 10 polymorphonuclear leucocytes per high power field ( $\times 100$ objective) in a urethral smear with no evidence of Neisseria gonorrhoeae. However, strong evidence, recently reviewed by Schachter, ${ }^{1}$ has now accumulated for a causative role for Chlamydia trachomatis in up to $50 \%$ of men with NGU and for the sexual transference of this agent.

In women, the commonest site of chlamydial infection (as in gonorrhoea) is the cervix, ${ }^{2}$ the site of greatest coital contact, but $C$ trachomatis may also be isolated-although less frequently-from the rectum, ${ }^{4}$ the urethra, ${ }^{5}$ and Bartholin's ducts. ${ }^{6}$

Criteria similar to those used in the diagnosis of NGU in men cannot be applied to cervicitis because the endocervical secretion contains polymorphonuclear leucocytes which vary in number according to hormonal factors and coital history. Until the clinical signs of infection and related symptoms were investigated in conjunction with rapid tissue culture

Address for reprints: Dr I A Tait, Department of Venereology, Royal Liverpool Hospital, Prescot Street, Liverpool L7 8XP

Received for publication 25 June 1979 procedures for chlamydial isolation (based on methods of Gordon and Quan ${ }^{7}$ ) the diagnosis of nongonococcal cervicitis in women was unsatisfactory owing to the absence of a known aetiological agent.

The difficulties associated with interpreting clinical signs in the cervix have previously been discussed in detail. ${ }^{8}$ The same method of categorising the state of the ectocervix is used here; it is based upon the concept that ectopy (erosion) is not a pathological condition but simply ectopic columnar epithelium which extends from the endocervix to the ectocervix. ${ }^{910}$ The redness which is associated with such ectopy-and sometimes thought to represent inflammation-results from the sub-mucosal capillary bed being viewed through a single layer of columnar epithelium instead of many layers of squamous epithelium. Irregularity of outline with peninsulae and islands of squamous epithelium together with Nabothian follicies (ducts of mucus glands blocked by metaplastic squamous epithelium) indicates metaplasia which is, in most cases, physiological but may be dysplastic. ${ }^{11}$ When an area of ectopy is oedematous and congested and bleeds, we have called it "hypertrophic". This appearance was first described as "cobblestone" by Dunlop, ${ }^{12}$ who also reported the presence of "follicles" on colposcopical examination of the cervix. Together with mucoid or 
mucopurulent endocervical discharge these two signs, singly or combined, indicate endocervicitis.

At present there is no consistent management of sexual contacts of men with NGU. Some physicians refer all contacts for investigation and give treatment to all on epidemiological grounds, irrespective of clinical or microbiological findings. Others are selective in both their referrals and their treatment. Many physicians have been deterred from giving epidemiological treatment-in the absence of symptoms-as candidosis might ensue. However, women with gonorrhoea are commonly asymptomatic and without clinical signs. They are treated when $N$ gonorrhoeae is isolated because it has been established that failure to treat may lead to serious consequences for the patient herself and for the community. It is therefore important that the pathogenic role of $C$ trachomatis in women should be defined; (a) to establish the need for the treatment of known infections; and (b) to provide information for physicians who may have to manage their patients without isolation facilities.

This paper gives the results of an investigation of chlamydial infection in 202 women who were sexual contacts of men with NGU with particular regard to: (a) the incidence of clinical signs and their response to treatment in patients from whom $C$ trachomatis was isolated; (b) the presence of concurrent infection; and (c) the incidence of chlamydial infection in patients with cervical ectopy and in those taking contraceptive steroids and the possible interrelationship of these two factors on the isolation rate of this agent.

\section{Patients and methods}

\section{CLINICAL INVESTIGATIONS}

The group of women examined consisted of 202 contacts of men with NGU who attended Liverpool Royal Infirmary consecutively on specified days. All the male contacts had been diagnosed in sexually transmitted diseases (STD) clinics where facilities for isolation of $C$ trachomatis were not available. Women who had received antibiotics in the four preceding weeks were excluded. Known cases or contacts of gonorrhoea were also excluded as that infection can also cause endocervicitis.

In this group of women, 169 presented with contact slips; the remainder attended of their own accord, or were referred by another doctor, and gave a history that their sexual contact was attending a male STD clinic. In these cases, the diagnosis was always obtained from the clinic named.

Swabs for detection of $N$ gonorrhoeae were taken from the urethra and endocervix on at least two separate occasions and used to inoculate a selective medium containing antibiotics (London Analytical and Bacteriological Media Ltd, London) and make a smear for Gram staining. All patients were investigated for syphilis by conventional methods and for trichomoniasis and yeast infection by inoculation of Feinberg-Whittington medium. (Yeast infection was only recorded if cultures gave positive results even when clinical signs and symptoms suggesting the condition were present.) Swabs for culture for $C$ trachomatis were taken from the endocervical canal and, in addition, rubbed on any ectopic columnar epithelium as previously described. ${ }^{6}$ Swabs were not taken from the urethra.

\section{LABORATORY TESTS}

Swabs for culture for $C$ trachomatis were immediately placed in $2-3 \mathrm{ml}$ of transport medium ${ }^{13}$ and stored directly at $4^{\circ} \mathrm{C}$ until inoculated into tissue culture. This was usually done two to four hours after the swab had been taken but occasionally after storage for 24 hours.

Swab contents were thoroughly dispersed into transport medium and $0.4 \mathrm{ml}$ were inoculated on to each of two 16-mm coverslip cultures of replicating McCoy cells (that is, cells not pre-treated by $x$-irradiation or any anti-replicative chemical agents). Centrifugation-assisted absorption of the inoculum on to the McCoy cells as well as incubation conditions and method of examination of inoculated cultures after 48-72 hours' incubation have all been described previously. ${ }^{14}$

In all cases, the total number of intracellular inclusions of $C$ trachomatis recovered from each clinical specimen on the McCoy coverslip culture was counted. The inclusions detected represent a single cycle of development; their number therefore reflects the number of infective particles in the original cervical swab and is a direct measure of the number of particles being shed from the lesion. The purpose of this quantitative procedure was (a) to check the sensitivity and reproducibility of the laboratory method and (b) to have additional data against which the severity, response to treatment, and possibility of relapse might be assessed.

In all cases, the results represent the primary inoculation of specimens in tissue culture. No second passage from tissue culture to further tissue culture was performed to avoid any risk of false-positive results by cross-contamination.

\section{CLINICAL SIGNS}

The clinical signs were recorded on the request form and case sheet at the time of sampling.

The state of the ectocervix has been recorded in three categories: no ectopy, simple ectopy, and hypertrophic ectopy (Figs 1-3). The contents of the 


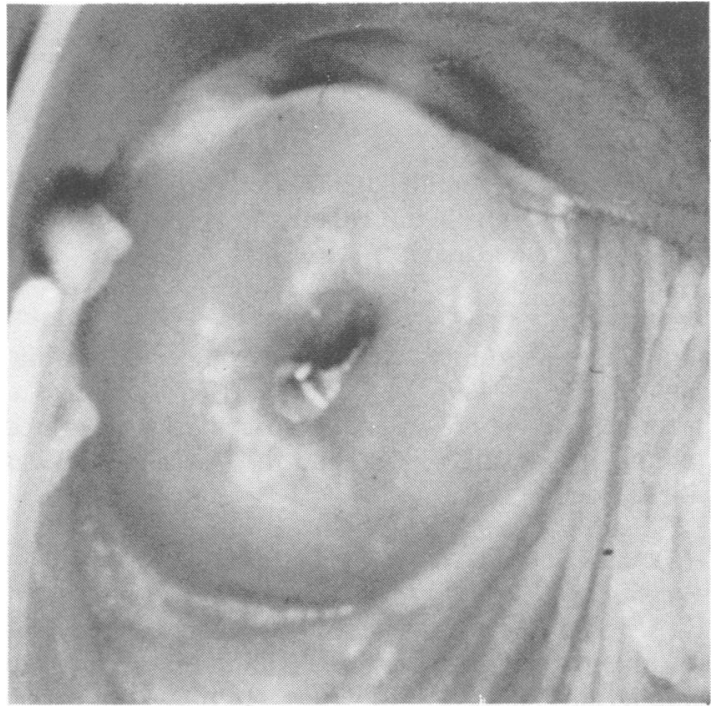

FIG 1 Cervix showing no ectopy.

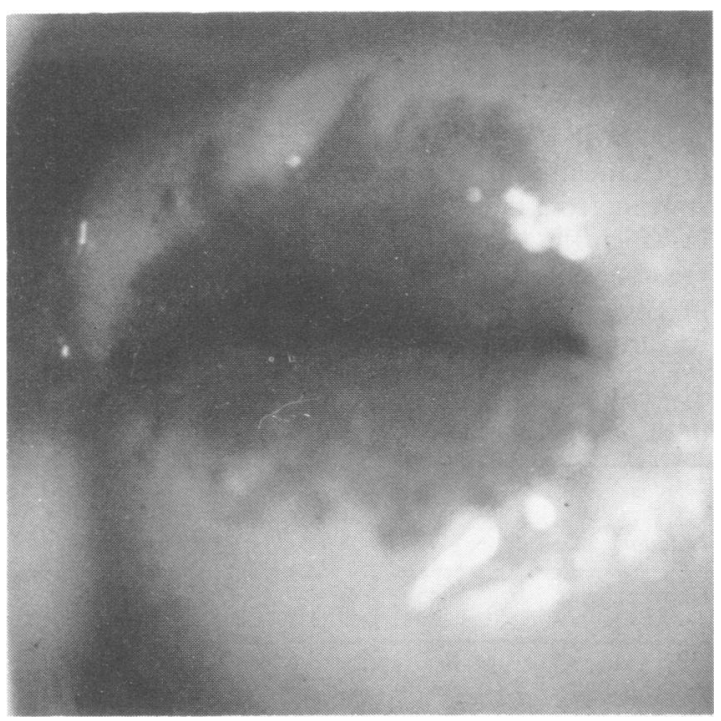

FIG 2 Cervix showing simple ectopy.

endocervix have been recorded in three categories; clear mucus, cloudy mucus, and mucoid or mucopurulent discharge (Figs 4 and 5). In examining the cervical contents, care was taken to remove discharge extruding from the cervix before the contents of the canal were assessed and sampled. Cervical secretion spreading from the os into the vagina becomes contaminated by vaginal flora, thus appearing mucopurulent in some cases, whereas behind this clear mucus may be seen in the canal.

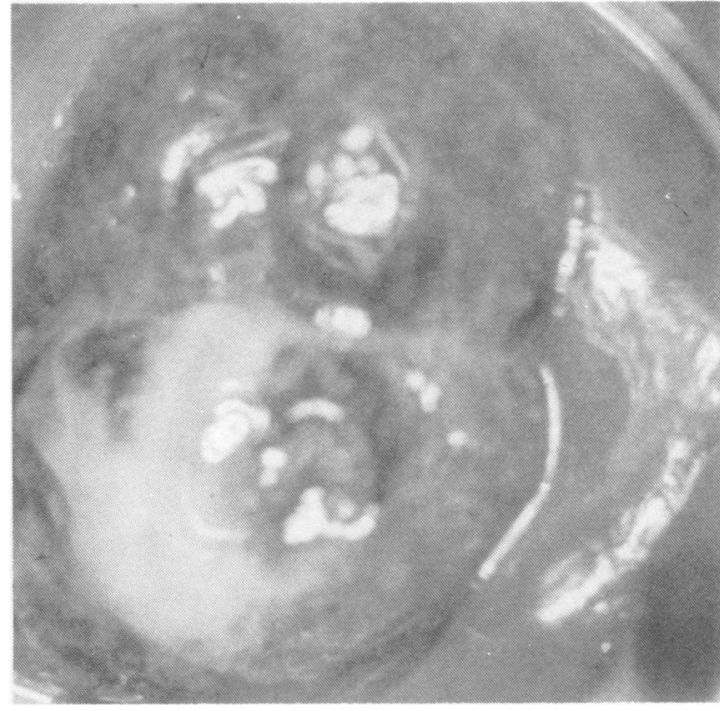

FIG 3 Cervix showing hypertrophic ectopy with endocervical mucopus. (C trachomatis isolated.)

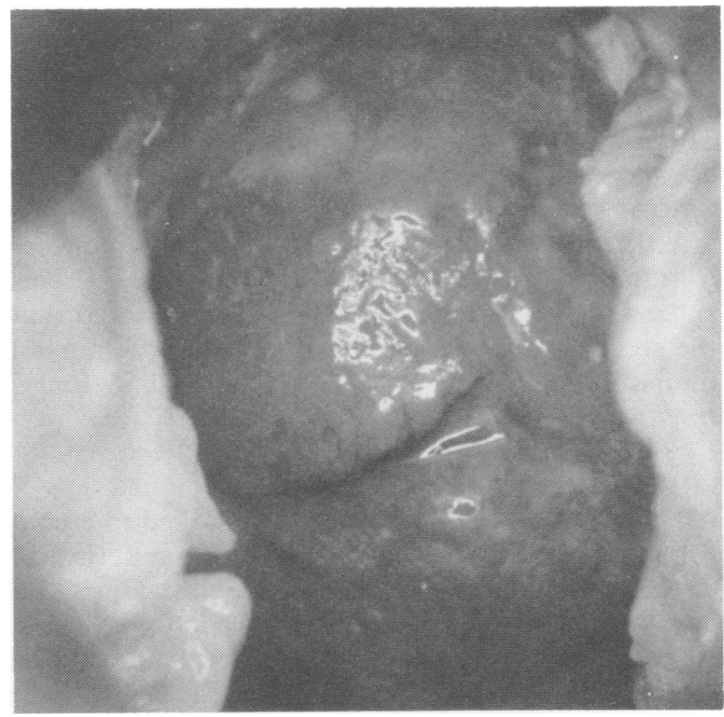

FIG 4 Cervix showing clear mucus with simple ectopy.

TREATMENT

Routine treatment of chlamydia-positive women was with oxytetracycline hydrochloride tablets $250 \mathrm{mg}$ six-hourly for 21 days. Pregnant women were not given oxytetracycline but received erythromycin BP $250 \mathrm{mg}$ six-hourly. Treatment was given for 21 days as this is the longest course advised for men with NGU and we did not want possible inadequate treatment to be a cause of persisting clinical signs or chlamydial reisolation or both. 


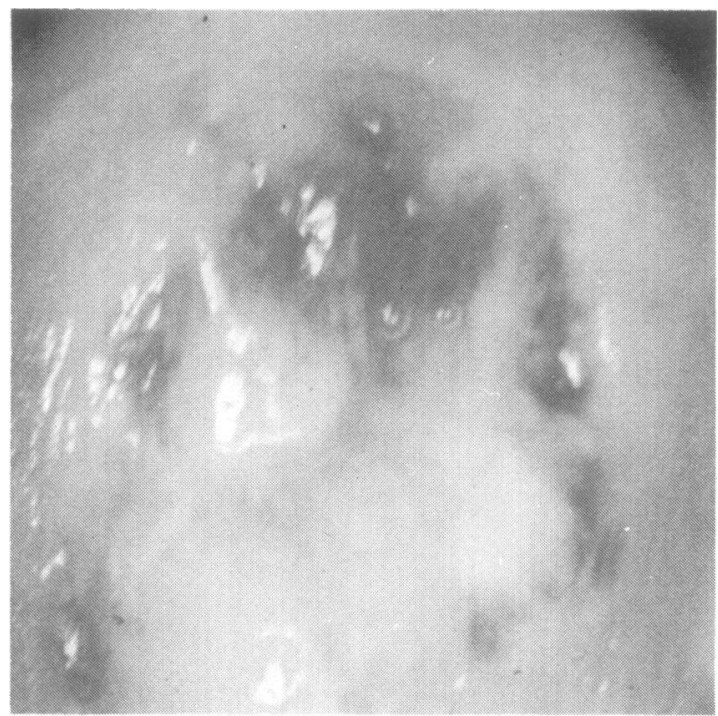

FIG 5 Cervix showing endocervical mucopus with simple ectopy.

Patient compliance can be a problem with such prolonged treatment. To assess this, blood samples were taken for serum tetracycline estimation at 14 or 21 days in 26 women. Patients were not told in advance that the test was to be carried out; hence the time of venepuncture varied from two to five hours after the last dose. The range of tetracycline concentrations was $0 \cdot 53-2 \cdot 01 \mu \mathrm{g}$ per $\mathrm{ml}($ mean $=1 \cdot 21)$. This suggests that patient compliance was good and that the serum concentration was satisfactory (minimum inhibitory concentration of oxytetracycline for $C$ trachomatis $=0 \cdot 2 \mu \mathrm{g} / \mathrm{ml}^{15}$ ).

\section{FOLLOW-UP}

All chlamydia-positive patients were asked to attend for review to check whether or not candidosis had developed and to assess the response to treatment on day 14 (of the course of treatment), on day 28 (that is, seven days after completion of treatment), twice more at three-weekly intervals, and subsequently at six weeks, a total of three months' post-treatment observation. Several patients agreed to co-operate by continuing to attend at three-monthly intervals and others returned with fresh symptoms or requesting reinvestigation within that time.

Specimens were taken for culture for $C$ trachomatis, $N$ gonorrhoeae, Trichomonas vaginalis, and Candida species on each post-treatment visit.

STATISTICAL METHODS

Statistical comparisons were made using the $\chi^{2}$ test with Yates's correction.

\section{Results}

C trachomatis was isolated from $70(35 \%)$ of the 202 women.

AGE

The age range for all 202 women was 16-46 years (mean 25 years); in the chlamydia-positive group it was 16-37 years (mean 23 years).

\section{MARITAL STATE}

One hundred and ten women were single (chlamydiapositive $36 \%$ ) and 68 were married (chlamydiapositive $28 \%$ ), 23 were divorced or separated (chlamydia-positive $39 \%$ ), and the status of one was unrecorded.

\section{HORMONAL FACTORS}

Pregnancy

Five patients were pregnant; two (one chlamydiapositive) were in the first trimester, two (both chlamydia-negative) in the second, and one (chlamydia-negative) in the third.

\section{Menstrual cycle}

No significant difference was found in the chlamydial isolation rates in successive weeks of the menstrual cycle.

In those 184 women with a regular cycle of 28 days $( \pm 2)$, the month was divided into four weeks, week 1 starting from the first day of menstruation. The week in which the swab for $C$ trachomatis was taken was recorded in each case. The isolation rates are shown in Table I. In 18 ( $21 \%$ chlamydia-positive) the cycle was irregular.

TABLE I Isolation of C trachomatis in relation to the week of the menstrual cycle

\begin{tabular}{llllll}
\hline & \multicolumn{4}{c}{ Menstrual cycle (week) } & \\
\cline { 2 - 5 } Isolation & 1 & 2 & 3 & 4 & Total \\
\hline No of patients & 45 & 66 & 42 & 31 & 184 \\
Chlamydia-positive (\%) & $17(38)$ & $23(35)$ & $15(36)$ & $9(29)$ & $64(35)$ \\
\hline
\end{tabular}

\section{Oral contraception}

At the time of examination, 99 women $(48 \cdot 7 \%$ chlamydia-positive) were taking oral contraceptives. The methods of contraception for all 202 patients and the distribution of these methods in relation to chlamydial isolation is shown in Table II.

The chlamydial isolation rate was significantly higher in women taking oral contraceptives than in (a) those not using oral contraception $\left(\chi_{1}^{2}=10 \cdot 44\right.$, $\mathrm{P}=0.0012$ ); (b) those using barrier methods $\left(\chi_{1}^{2}=8 \cdot 51, P=0 \cdot 0035\right)$; and (c) those using other methods, excluding barrier methods $\left(\chi_{1}^{2}=5 \cdot 91\right.$, $P=0 \cdot 015$ ). 
TABLE II Isolation of $C$ trachomatis in relation to method of contraception

\begin{tabular}{lccc}
\hline \multirow{2}{*}{$\begin{array}{l}\text { Method of } \\
\text { contraception }\end{array}$} & $\begin{array}{l}\text { No of } \\
\text { patients }\end{array}$ & \multicolumn{2}{c}{ Chlamydia-positive } \\
\cline { 4 - 4 } & 52 & 15 & 29 \\
\hline None & 99 & 46 & 49 \\
$\begin{array}{l}\text { Oral contraception } \\
\begin{array}{l}\text { Stopped oral contraception } \\
\text { in past month }\end{array}\end{array}$ & 7 & 3 & 43 \\
$\begin{array}{l}\text { Barrier } \\
\text { Tubal ligation and IUCD }\end{array}$ & 18 & 1 & $5 \cdot 6$ \\
$\begin{array}{l}\text { Not known } \\
\text { Total }\end{array}$ & 25 & 5 & 20 \\
\hline
\end{tabular}

IUCD = intrauterine contraceptive device

Despite the difference in percentage isolation between those using barrier methods and those using no contraception, the difference in proportions is not significant at $5 \%\left(\chi_{1}^{2}=2 \cdot 90, P=0 \cdot 089\right)$ but the lack of significance may be due only to the small numbers in the group using barrier methods.

\section{SYMPTOMS}

The incidence of symptoms and their distribution in relation to chlamydial isolation is shown in Table III. No significant difference was found in the isolation rates in relation to any particular symptom.

TABLE III Distribution of symptoms, appearance of the ectocervix, contents of the endocervix, and incidence of concurrent infections in relation to isolation of $C$ trachomatis

\begin{tabular}{|c|c|c|c|}
\hline & $\begin{array}{l}\text { No of } \\
\text { patients }\end{array}$ & $\begin{array}{l}\text { No } \\
\text { chlamydia- } \\
\text { positive }\end{array}$ & $\begin{array}{l}\% \text { of } \\
\text { positive }\end{array}$ \\
\hline \multicolumn{4}{|l|}{ Symptoms* } \\
\hline None & 103 & 34 & 49 \\
\hline Discharge & 61 & 22 & 31 \\
\hline Irritation and soreness & 31 & 17 & 24 \\
\hline Urinary & 24 & 11 & 16 \\
\hline Abdominal pain & 17 & 5 & 7 \\
\hline Postcoital bleeding & 3 & 1 & $1 \cdot 4$ \\
\hline Dyspareunia & 3 & 2 & 3 \\
\hline \multicolumn{4}{|l|}{ Appearance of ectocervix } \\
\hline No ectopy & 95 & 21 & 30 \\
\hline Simple ectopy & 87 & 36 & 51 \\
\hline Hypertrophic ectopy & 17 & 13 & 19 \\
\hline Not known & 3 & 0 & 0 \\
\hline Total & 202 & 70 & 100 \\
\hline \multicolumn{4}{|l|}{ Endocervical contents } \\
\hline Clear & 101 & 27 & 39 \\
\hline Cloudy & 56 & 14 & 20 \\
\hline Mucopus and mucoid & 35 & 26 & 37 \\
\hline Blood & 10 & 3 & 4 \\
\hline Total & 202 & 70 & 100 \\
\hline \multicolumn{4}{|l|}{ Concurrent infections } \\
\hline None & 110 & 40 & 57 \\
\hline Candida spp & 61 & 16 & 23 \\
\hline Trichomonas vaginalis & 15 & 10 & 14 \\
\hline Warts (cervical and vulval) & 10 & 4 & 6 \\
\hline Other & 0 & 0 & 0 \\
\hline Total & & 70 & 100 \\
\hline
\end{tabular}

*Patients may have had more than one symptom

\section{CLINICAL SIGNS}

\section{Ectocervix}

The appearance of the ectocervix in relation to the chlamydial isolation rate is shown in Table III. The isolation rate was significantly higher in those with (a) ectopy (simple and hypertrophic), $47 \%$ $\left(\chi_{1}^{2}=12 \cdot 5, \quad \mathrm{P}=0.0004\right) ;$ (b) simple ectopy, $41 \%$ $\left(\chi_{1}^{2}=6 \cdot 97, \mathrm{P}=0 \cdot 0083\right)$; and (c) hypertrophic ectopy, $76 \%\left(\chi_{1}^{2}=17 \cdot 67, P=0 \cdot 000026\right)$ than in those with no ectopy, $22 \%$.

\section{Endocervical contents}

The distribution of contents in relation to the chlamydial isolation rate is shown in Table III. The isolation rate was significantly higher in those with mucopus (74\%) than in those with clear and cloudy mucus $(26 \%)\left(\chi_{1}^{2}=27 \cdot 14, \mathrm{P}=0 \cdot 0000045\right)$.

\section{Salpingitis}

Seventeen patients complained of abdominal pain or discomfort (five were chlamydia-positive). Only four of these had clinical signs of salpingitis (two were chlamydia-positive.)

\section{EFFECTS OF ORAL CONTRACEPTION/CERVICAL ECTOPY ON CHLAMYDIAL ISOLATION}

To assess the possible interrelationship between oral contraception and cervical ectopy, both of which individually were found to be highly significant in the isolation of $C$ trachomatis, the four possible categories were compared and analysed statistically (for this purpose simple and hypertrophic ectopy were combined) (Table IV):

(1) The isolation rates in patients with $(57 \cdot 1 \%)$ and without $(30 \cdot 2 \%)$ oral contraception in the presence of cervical ectopy $\left(\chi_{1}^{2}=6 \cdot 06, P=0 \cdot 014\right)$; (2) The isolation rates in patients with $(57 \cdot 1 \%)$ and without $(27 \cdot 3 \%)$ ectopy in those taking oral contraception $\left(\chi_{1}^{2}=6 \cdot 3, \mathrm{P}=0 \cdot 012\right)$;

(3) The isolation rates in women with (27.3\%) and without $(16 \cdot 4 \%)$ oral contraception in the absence of ectopy $\left(\chi_{1}^{2}=0.97, \mathrm{P}=0.32\right)$;

(4) The isolation rates in patients with $(30 \cdot 2 \%)$ and without $(16 \cdot 4 \%)$ ectopy in the absence of oral contraception $\left(\chi_{1}^{2}=2 \cdot 06, \mathrm{P}=0 \cdot 15\right)$.

Thus neither oral contraception in the absence of ectopy, nor ectopy in the absence of oral contraception, is associated with a significant increase in the isolation rate. On the other hand, a significant increase is associated both with oral contraception when ectopy is present and with ectopy when oral contraception is being used. Oral contraception and ectopy may be said to act additively, neither being associated with a significant increase in the isolation rate when acting alone but jointly being associated 
with a significant increase when acting simultaneously.

The isolation rates in the above categories (Table IV) differ to a very highly significant extent $\left(\chi_{3}^{2}=22 \cdot 95, \mathrm{P}=0 \cdot 000041\right)$.

TABLE IV C trachomatis isolation in relation to ectopy and oral contraception

\begin{tabular}{|c|c|c|c|}
\hline \multirow[b]{2}{*}{ Comparison } & \multirow{2}{*}{$\begin{array}{l}\text { No of } \\
\text { patients }\end{array}$} & \multicolumn{2}{|c|}{ Chlamydia-positive } \\
\hline & & No & $\%$ \\
\hline Ectopy & 99 & 45 & $45 \cdot 5$ \\
\hline With OC & 56 & 32 & $57 \cdot 1$ \\
\hline Without OC & 43 & 13 & $30 \cdot 2$ \\
\hline No ectopy & 94 & 19 & $20 \cdot 2$ \\
\hline With OC & 33 & 9 & $27 \cdot 3$ \\
\hline Without OC & 61 & 10 & $16 \cdot 4$ \\
\hline \multicolumn{4}{|l|}{ Total } \\
\hline With OC & 89 & 41 & $46 \cdot 1$ \\
\hline Without OC & 104 & 23 & $22 \cdot 1$ \\
\hline
\end{tabular}

OC $=$ oral contraception

\section{CONCURRENT INFECTIONS}

The presence of concurrent infection in relation to chlamydial isolation is shown in Table III. Only normal flora was found in only 110 patients (35\% chlamydia-positive). A significant increase in the isolation rate was found only in the presence of $T$ vaginalis $\left(\chi_{1}^{2}=5 \cdot 89, \mathrm{P}=0 \cdot 15\right) . N$ gonorrhoeae was present in seven patients, of whom three were chlamydia-positive at the time of their first visit.

WHOLE-COVERSLIP COUNT (WCC)

The range for the 70 chlamydia-positive patients was 1-100 000 inclusions per whole coverslip. The possibility that the degree of infection (as represented by the WCC) may vary according to conditions such as the presence or absence of oral contraception and clinical signs in the cervix was considered. The mean counts of the WCC in these conditions are given in Table V.

TABLE V Mean whole-coverslip counts in certain conditions

\begin{tabular}{lc}
\hline Condition & Mean count \\
\hline Oral contraception & \\
Present & 6185 \\
Absent & 2071 \\
Hypertrophic ectopy & 4895 \\
Present & 4906 \\
Absent & 10727 \\
Endocervical mucopus & 1745 \\
Present & \\
Absent & \\
\hline
\end{tabular}

FOLLOW UP

Thirty-eight women were followed up for 2-14 months. $C$ trachomatis was reisolated from five patients (Table VI) and there was a strong possibility of reinfection in four of the five cases.*

TABLE vi Post-treatment follow up

\begin{tabular}{lll}
\hline & $\begin{array}{l}\text { No of } \\
\text { patients }\end{array}$ & $\begin{array}{l}\text { Chlamydial } \\
\text { reisolation }\end{array}$ \\
\hline $\begin{array}{l}\text { Duration of treatment } \\
\text { (months) }\end{array}$ & & \\
$<2$ & 8 & $2^{*}$ \\
$2-3$ & 4 & 1 \\
$4-6$ & 15 & 1 \\
$7-8$ & 7 & \\
$9-10$ & 1 & 1 \\
$11-12$ & 1 & 1 \\
$>12$ & 2 & $1^{*}$ \\
No of visits & 4 & $3^{*}$ \\
1 & 11 & 1 \\
2 & 6 & 1 \\
3 & 8 & \\
4 & 4 & \\
5 & 3 & \\
6 & 1 & \\
7 & 1 & \\
8 & & \\
\hline
\end{tabular}

*Two reisolates from one patient

\section{Clinical signs}

Ectocervix. Of 12 patients with hypertrophic ectopy, 11 reverted to simple ectopy and metaplasia was complete in one.

Contents of the os. Of those patients followed up after treatment, of 20 endocervices previously containing mucopus, eight became clear, 11 became cloudy, and one contained mucoid material.

\section{Yeast infection}

Of 70 chlamydia-positive patients, 16 had positive cultures for Candida species when the chlamydial infection was diagnosed; twenty-five patients who had negative results for yeasts initially did not attend for follow-up investigations. Of the remaining 29 chlamydia-positive women with negative results for yeasts, who were treated either with tetracycline hydrochloride or erythromycin (two), four (14\%) (all taking tetracycline) developed yeast infection.

\section{Discussion}

$C$ trachomatis was isolated from $35 \%$ of the 202 female sexual contacts of unselected men with NGU. Isolation rates of $22-42 \%{ }^{3}{ }^{16-18}$ have previously been reported in different parts of the world. Differences,

*Details of personal case histories may be obtained from Dr I A Tait. 
however, occur in the reporting of clinical signs in the cervix associated with chlamydial infection. Signs of cervicitis have been recorded in $62-89 \% 171920$ but were also present in $58 \%$ of uninfected women who were contacts of $\mathrm{NGU}^{17}$ and in $56 \%$ of control women attending a family planning clinic. ${ }^{20}$ However, cervical ectopy (erosion, cervical discontinuity) was included as an abnormal clinical sign in all these reports and may account for these differences.

The site of the squamocolumnar junction is laid down at the time of organogenesis and ectopy is found in infants, children, and virgins. ${ }^{9}$ At certain times, particularly at puberty and first pregnancy, the ectopic columnar epithelium is replaced by squamous epithelium (squamous metaplasia, Fig 6) with the result that ectopy is less common in the older woman. ${ }^{9}$ In a study planned to determine the prevalence and significance of cervical ectopy in women attending family planning clinics in Edinburgh, ectopy was found in $37 \%$ of 1400 women and was significantly associated with younger age groups, greater parity, and oral contraception. ${ }^{21}$ There was no significant association with the presence of aerobic or anaerobic bacteria, $T$ vaginalis, or yeasts.

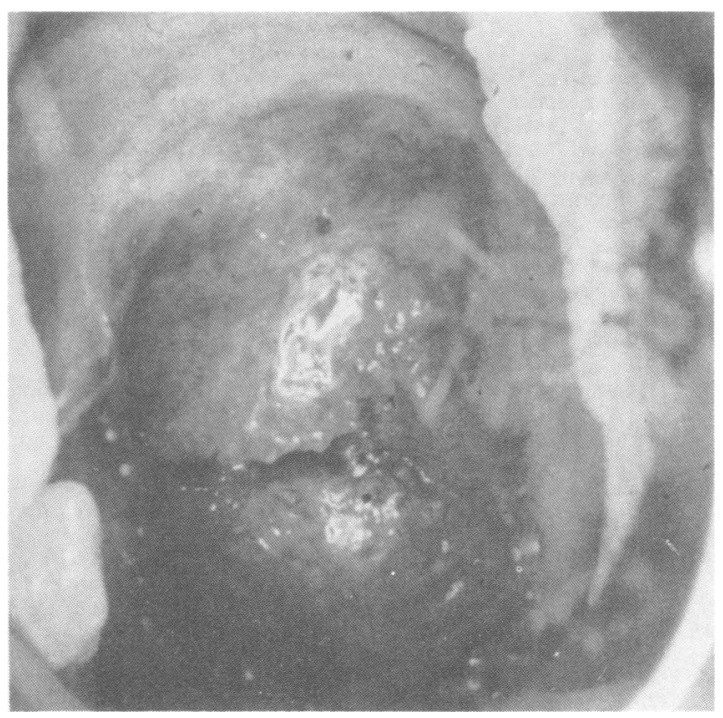

FIG 6 Cervix showing metaplasia and simple ectopy with clear mucus.

If signs of cervicitis are narrowly defined on macroscopic examination as endocervical pus within the canal and oedema of the areas covered by columnar epithelium (hypertrophic ectopy or cobblestone appearance as described by Dunlop) $)^{12}$ there is a highly significant association between cervicitis and the isolation of $C$ trachomatis. In this series of consecutive cases, mucopus was found in $37 \%$ of chlamydia-positive cases compared with $7 \%$ of chlamydia-negative cases $(P=0.0000045)$, and oedema (hypertrophic ectopy) in 19\% of chlamydiapositive compared with only $3 \%$ of chlamydianegative cases $(P=0 \cdot 000026)$. The incidence of endocervical mucopus is similar to that found in women with chlamydia-negative gonorrhoea examined in this unit. In each infection, macrosopic evidence of the endocervical infection is absent in $50-60 \%$. After treatment of the chlamydial infection, clinical signs of oedema and mucopus disappeared in all but one patient.

Symptoms associated with endocervicitis are difficult to interpret because the area of susceptible columnar epithelium, and therefore the consequent amount of mucopus which may be produced, is relatively small. Excessive mucus production by the cervical columnar epithelium due to the progestational effect of contraceptive steroids, or due to a large area of ectopy, may result in a discharge which is not associated with infection of any kind. In addition, even a mild vaginitis due to common vaginal pathogens such as $T$ vaginalis or yeasts may result in a noticeable discharge owing to the large area of squamous epithelium of the vagina affected.

Consequently, symptoms may bear little relationship to cervical pathology in a large number of women. In this series, no significant relationship was found between the presence of chlamydial infection in the cervix and any of the symptoms. Similar findings have been reported by others. ${ }^{2022} 23$ Indeed Burns et al $^{16}$ reported a significant absence of symptoms in the presence of chlamydial infection. However, Paavonen et al $^{19}$ found chlamydia-positive gynaecological patients had significantly more ocular and urethral symptoms than chlamydia-negative patients.

Thus, $C$ trachomatis infection appears to be associated with certain well-defined signs of cervicitis in some patients and probably these signs are caused by that infection. On the other hand, with ectopy there is also a definite relation to chlamydial infection but, for reasons already discussed, simple ectopy cannot be considered to be part of the sign-complex of cervicitis. It seems possible that ectopy may be one of many possible interrelated factors which allow infection to be more easily acquired. For example, the virulence of particular serotypes of chlamydia, the immune status of the patient, and anatomical and histological variations may all influence the ease with which infection of the tissues is established. Harkness $^{24}$ found a higher prevalence of hypospadias 
(a condition in which columnar epithelium extends to the external urethral surface since the fossa navicularis is absent) in patients with NGU and gonorrhoea than in the normal population. Cervical ectopy may have a similar effect in chlamydial infection and may be more important than in gonorrhoea because of the intracellular developmental cycle of chlamydia.

Our findings indicate that only in patients in whom the two factors, contraceptive steroids and ectopy, are present is there a significant increase in the isolation rate of $C$ trachomatis $(\mathrm{P}=0 \cdot 00004)$. Neither factor in the absence of the other is significant. Apart from an implied absence of any barrier to infection of the cervix, oral contraceptive steroids may facilitate cervical infection by their progestational effect, which is similar to that produced in the first trimester of pregnancy. They produce an excessive outflow of alkaline mucus from the endocervical glands and increase the bulk of the cervix, producing eversion with further ectopy. It is noteworthy that steroids added to McCoy tissues cultures infected with $C$ trachomatis increase the size and number of inclusions developing. ${ }^{25}$

The interdependence of several varying factors may explain some of the disparity about the effect of oral contraceptives on the chlamydial isolation rate previously reported. 16172023

Like Oriel et $a l,{ }^{23}$ but unlike Hilton et $a l,{ }^{20}$ we found no variation in the isolation rate according to the week of the menstrual cycle.

The increased chlamydial isolation rate in the presence of $T$ vaginalis may reflect the frequency with which multiple sexually transmissible agents are isolated in promiscuous patients. ${ }^{26}$ Others have found no relation between the chlamydial isolation rate and any other concurrent nongonococcal infection. ${ }^{23}$

The mean whole-coverslip counts were raised in patients taking oral contraceptive steroids and in the presence of endocervical mucopus but not in the presence of hypertrophic ectopy. It is possible that oral contraceptive steroids facilitate chlamydial cervical infection, and the presence or absence of endocervical mucopus indicates the severity of the infection, whereas hypertrophic ectopy merely indicates a general host-response to infection in some patients. The possible influence of these clinical factors on the degree of chlamydial replication in infected women will be discussed separately.

In addition to causing acute cervicitis $C$ trachomatis has been isolated from the fallopian tubes in cases of pelvic inflammatory disease confirmed at laparoscopy and associated with a fourfold rise in chlamydial antibody titre. ${ }^{27}$ Clearly, it is potentially a serious pathogen in women.
This work was supported by a project grant from the Medical Research Council. We would like to thank Dr C D Alergant, Dr E Annels, Dr O P Arya and Dr $F$ Lancely for allowing us access to their male patients' case sheets. We are indebted to Professor Percival and Dr R E Rewell for microbiological investigations, to Dr G C Turner for serological tests for syphilis, to Dr T N Calvey of the Department of Clinical Pharmacology for serum tetracycline estimations, and to Mr C R West for help with statistical analysis.

\section{References}

1. Schachter J. Chlamydial infections. N Engl J Med 1978; 298: 428-34.

2. Dunlop EMC, Goldmeier D, Darougar S, Jones BR. Chlamydia infection of the genital tract in the mothers and fathers of babies suffering from ophthalmia neonatorum due to TRIC agent. In: Catterall RD, Nicol CS (eds). Sexually Transmitted Diseases. London: Academic Press, 1976: 83-8.

3. Terho P. Chlamydia trachomatis in non-specific urethritis. $\mathrm{Br}$ J Vener Dis 1978; 54: 251-6.

4. Dunlop EMC, Hare MJ, Darougar S, Jones BR, Rice NSC. Detection of Chlamydia (Bedsonia) in certain infections of man. II Clinical study of genital tract, eye, rectum and other sites of recovery of Chlamydia. J Infect Dis 1969; 120: 463.

5. Dunlop EMC, Darougar S, Hare MJ, Treharne JD, Dwyer $\mathrm{RStC}$. Isolation of Chlamydia from the urethra of a woman. $\mathrm{Br}$ Med J 1972; 7: 386.

6. Davies JA, Rees E, Hobson D, Karayiannis P. Isolation of Chlamydia trachomatis from Bartholin's ducts. Br J Vener Dis 1978; 54: 409-13.

7. Gordon FB, Quan AL. Isolation of the trachoma agent in cell culture. Proc Soc Exp Biol Med 1965; 118: 254-9.

8. Rees E, Tait IA, Hobson D, Johnson FWA. Chlamydia in relation to cervical infection and pelvic inflammatory disease. In: Hobson D, Holmes KK, (eds). Non-gonococcal Urethritis and Related Infections. Washington DC: American Society for Microbiology, 1977: 67-76.

9. Coppleson M, Reid B. Preclinical Carcinoma of the Cervix Uteri. 1st ed. Oxford: Pergamon Press, 1967.

10. Singer A, Jordan JA. The anatomy of the cervix. In: Jordan JA, Singer A, eds. The Cervix. London: WB Sanders 1976: 13-36.

11. Singer A. The cervical epithelium during puberty and adolescence. In: Jordan JA, Singer A, (eds). The Cervix. London: WB Sanders 1976: 87-104.

12. Dunlop EMC, Al-Hussaini MK, Freedman A, et al. Infection by TRIC agent and other members of the Bedsonia group; Genital infection and disease of the eye. Trans Ophthalmol Soc UK 1966; 86: 321-34.

13. Richmond SJ. The isolation of Chlamydia sub group A (Chlamydia trachomatis) in irradiated McCoy cells. Med Lab Technol 1974; 31: 7-9.

14. Johnson FWA, Hobson D. Factors affecting the sensitivity of replicating McCoy cells in the isolation and growth of Chlamydia A. J Hyg (Lond) 1976; 76: 441-51.

15. Treharne JD, Day J, Yeo CK, Jones BR, Squires S. Susceptibility of Chlamydia to chemotherapeutic agents. In: Hobson $\mathrm{D}$, Holmes KK, (eds). Non-gonococcal Urethritis and Related Infections. Washington DC: American Society for Microbiology, 1977: 214-22.

16. Burns DCM, Darougar S, Thin RN, Lothian L, Nicol CS. Isolation of Chlamydia from women attending a clinic for sexually transmitted disease. Br J Vener Dis 1975; 51: 314-8.

17. Oriel JD, Reeve P, Miller A, Nicol CS. Chlamydial infections of the cervix. Br J Vener Dis 1974; 50: 11-16.

18. Holmes, KK, Handsfield HH, Wang S-P, et al. Etiology of non-gonococcal urethritis. N Engl J Med 1975; 292: 1199-205.

19. Paavonen J, Saikku P, Vesterinen E, Meyer B, Vartainen E, Saksela E. Genital chlamydial infections in patients attending a gynaecological outpatient clinic. Br J Vener Dis 1978; 54: 257-61. 
20. Hilton AL, Richmond SJ, Milne JD, Hindley F, Clarke SKR. Chlamydia $A$ in the female genital tract. Br J Vener Dis 1974; 50: $1-10$.

21. Goldacre MJ, Loudon N, Watt B, et al. Epidemiology and clinical significance of cervical erosion in women attending a family planning clinic. $B r$ Med $J 1978 ; 1: 748-50$.

22. Nayyar KC, O'Neill JJ, Hambling MH, Waugh MA. Isolation of Chlamydia trachomatis from women attending a clinic for sexually transmitted diseases. Br J Vener Dis 1976; 52: 396-98.

23. Oriel JD, Johnson AL, Barlow D, Thomas BJ, Nayyar K, Reeve P. Infection of the uterine cervix with Chlamydia trachomatis. J Infect Dis 1978; 137: 443-51.

24. Harkness AH. The pathology of gonorrhoea. $\mathrm{Br} J$ Vener Dis 1948; 24: 137-47.
25. Bushell AC, Hobson D. Effect of cortisol on the growth of $C$ trachomatis in McCoy cells. Infect Immun 1978; 21: 946-53.

26. Wentworth BB, Bonin P, Holmes KK, Gutman L, Wiesnef P, Alexander ER. Isolation of viruses, bacteria and other organisms from venereal disease clinic patients: methodology and problems associated with multiple isolations. Health $\mathrm{Lab}$ Sci 1973; 10: 75-81.

27. Mårdh P-A, Ripa KT, Wang S-P, Weström L. C trachomatis as an etiological agent in acute salpingitis. In: Hobson D Holmes KK, (eds). Non-gonococcal Urethritis and Related Infections. Washington DC: American Society for Microbiology, 1977: 77-83. 